\title{
Quantitative assay of enzymes in tissues
}

\author{
E. ANN BURGESS AND B. LEVIN
}

There are two main groups of conditions in which the determination of enzyme activities in tissues is necessary or desirable. They are (a) primary defects of enzyme synthesis and (b) alterations of enzyme activity secondary to damage of the cell. Since the time of Garrod, hereditary metabolic disorders have been recognized to be due to a defect of one or perhaps more enzymes, which may have farreaching metabolic consequences and produce multiple biochemical and other abnormalities. This communication is confined to enzyme assays using tissues from organs such as liver, kidney, or gastrointestinal mucosa and including the leucocytes of the blood. It excludes the examination of blood plasma, the enzymes of which are, of course, not synthesized there, but accumulate by leakage from the organs it bathes or from degradation of red and white blood cells. A general review of methods of enzyme assay is not attempted, but the principles of the methods used for individual enzyme assays are emphasized. Selection has been based on the special factors which must be taken into account in this field, eg, the limited amount of material available so that the sensitivity of a method is important, and the fact that tissues contain a mixture of enzymes as well as many different substrates. The methods of assay available for pure enzymes are not always applicable to a crude tissue homogenate.

\section{Tissues Used for Enzyme Assays (Table)}

The organ most commonly involved in hereditary metabolic disorders is the liver, which is therefore the tissue most frequently biopsied. A specimen can be obtained either by percutaneous needle aspiration or by open biopsy. It is always desirable to examine as many enzymes as possible of the metabolic sequence in which the block is thought to occur. This is necessary for two reasons. First, there not infrequently appears to be alteration of the activity of another enzyme of the pathway besides the defective one; this may be a genuine defect of two enzymes simultaneously, as has been reported in certain types of glycogen storage disease (Auerbach and DiGeorge, 1965; Parr, Teree, and Larner, 1965); or it may be the result of adaptation to changes in concentration of metabolites resulting from the

\begin{tabular}{|c|c|c|}
\hline Tissue & Advantage & Disadvantages \\
\hline \multicolumn{3}{|l|}{ Liver } \\
\hline Percutaneous biopsy & $\begin{array}{l}\text { Fairly readily } \\
\text { obtained }\end{array}$ & $\begin{array}{l}\text { Only } 10-20 \mathrm{mg} \\
\text { obtained }\end{array}$ \\
\hline Open biopsy & $\begin{array}{l}250-500 \mathrm{mg} \text { tissue } \\
\text { obtained }\end{array}$ & Hazards of operation \\
\hline Intestine & $\begin{array}{l}\text { Fairly readily obtained } \\
\text { Similar enzyme } \\
\text { pattern to liver }\end{array}$ & $\begin{array}{l}\text { Only } 20-30 \mathrm{mg} \\
\text { obtained }\end{array}$ \\
\hline White blood cells & $\begin{array}{l}\text { Readily available: } \\
\text { many enzymes present }\end{array}$ & $\begin{array}{l}\text { Very small amount of } \\
t \text { tissue obtained }\end{array}$ \\
\hline Red blood cells & $\begin{array}{l}\text { Very readily available } \\
\text { in large amounts }\end{array}$ & $\begin{array}{l}\text { Absence of many } \\
\text { enzymes }\end{array}$ \\
\hline Skin & $\begin{array}{l}\text { Fairly readily } \\
\text { available }\end{array}$ & $\begin{array}{l}\text { Proportion of living } \\
\text { tissue uncertain unless } \\
\text { the skin fibroblasts } \\
\text { are cultured }\end{array}$ \\
\hline Muscle & $250-500 \mathrm{mg}$ obtained & $\begin{array}{l}\text { Useful only in a } \\
\text { proportion of } \\
\text { conditions }\end{array}$ \\
\hline
\end{tabular}

Table Tissues used for enzyme assays

primary enzyme defect (see Fig. 3). Secondly, it is desirable to exclude a general deterioration of all the enzymes of the tissue by demonstrating that the presence of some are normal. An exhaustive investigation of this type is not often possible with the small amount of tissue, $10-20 \mathrm{mg}$, obtained by needle aspiration, whereas it can be achieved with 250-500 mg obtained by open operation.

It is sometimes inadvisable to subject patients to liver biopsy, and such a procedure may be even less justifiable when studying apparently healthy relatives. However, it is usually possible to remove $10-20 \mathrm{ml}$ of blood for the study of white or red blood cells, and this may be an acceptable alternative because an abnormal enzyme activity in the liver is often also manifest in leucocytes, and even (although perhaps less frequently) in red cells. For example, in cases of glycogen storage disease all the enzymes most commonly involved, except for glucose 6-phosphatase (EC3 .1.39), may be measured in leucocytes. Red blood cells are less useful from this point of view because they have lost a great many of the enzymes normally present in nucleated cells; nevertheless some enzymes which normally would be assayed in liver, eg, arginase (EC 3.5.3.1) or argininosuccinate lyase (EC 4.3.2.1), can be measured in red cells if a liver biopsy is not available. Apart from this, enzyme activities are assayed in red cells because of a primary 
enzyme defect of these cells, as for example in certain haemolytic anaemias.

Skin, another tissue which is relatively simple to obtain, may also show abnormal enzyme activities similar to those in liver or other organs. It has the drawback that it is difficult to assess what proportion of active tissue is present in the biopsy. It is, however, possible to grow skin fibroblasts in tissue culture, when results of enzyme assay can be related to cell numbers.

Jejunal biopsies are usually taken when malabsorption is suspected, in order to measure the enzymes concerned with the absorption of carbohydrate or protein. However, the jejunal mucosa has an enzyme pattern which resembles that of liver more closely than that of leucocytes, and it is sometimes examined instead of liver because a jejunal biopsy is more easily performed. A disadvantage is that the biopsies are very small, only $20-30 \mathrm{mg}$ in weight. Muscle biopsies are readily obtained when enzyme patterns are to be studied in muscle disorders.

\section{Enzymes of Similar Function in Different Tissues}

The major disadvantage of using tissues other than liver is that enzyme patterns are not necessarily uniform among organs. The early assumption that a genetic defect resulting in an enzyme deficiency was uniformly present in all the cells of the body is not now thought to be correct. Although an enzyme found to be abnormal in white blood cells, skin, or jejunum is generally, although not invariably, abnormal the liver, the reverse cannot be assumed; for enzymes have been found to be abnormal in liver whe normal in leucocytes or jejunum of the same patient. Thus a normal glycogen phosphorylase (EC 2.4.1.1\%) activity in white blood cells of a case of glycogen storage disease cannot be accepted as proof that $n$ abnormality of the liver enzyme exists (Öckerma Jelke, and Kaijser, 1966). Similarly, in one case off fructosaemia, the liver fructose 1-phosphate aldolasso (EC 4.1.2.7) activity was reduced, while the activity in jejunal mucosa was normal (Levin, Snodgrase Oberholzer, Burgess, and Dobbs, 1968). Such divergence between two tissues may be related to the existence of isoenzymes, only one of which may be affected.

Study of Other Properties of Enzymes than Activity

A metabolic defect may sometimes occur when the enzyme activity in vitro appears to be normal or on slightly below the normal range. However, provide sufficient tissue is available it may be possible show by the measurement of other properties of the enzyme that the enzyme is abnormal. For exargpty the Michaelis constant $\left(\mathrm{K}_{\mathrm{m}}\right)$ of an enzyme may be determined as a measure of its affinity for

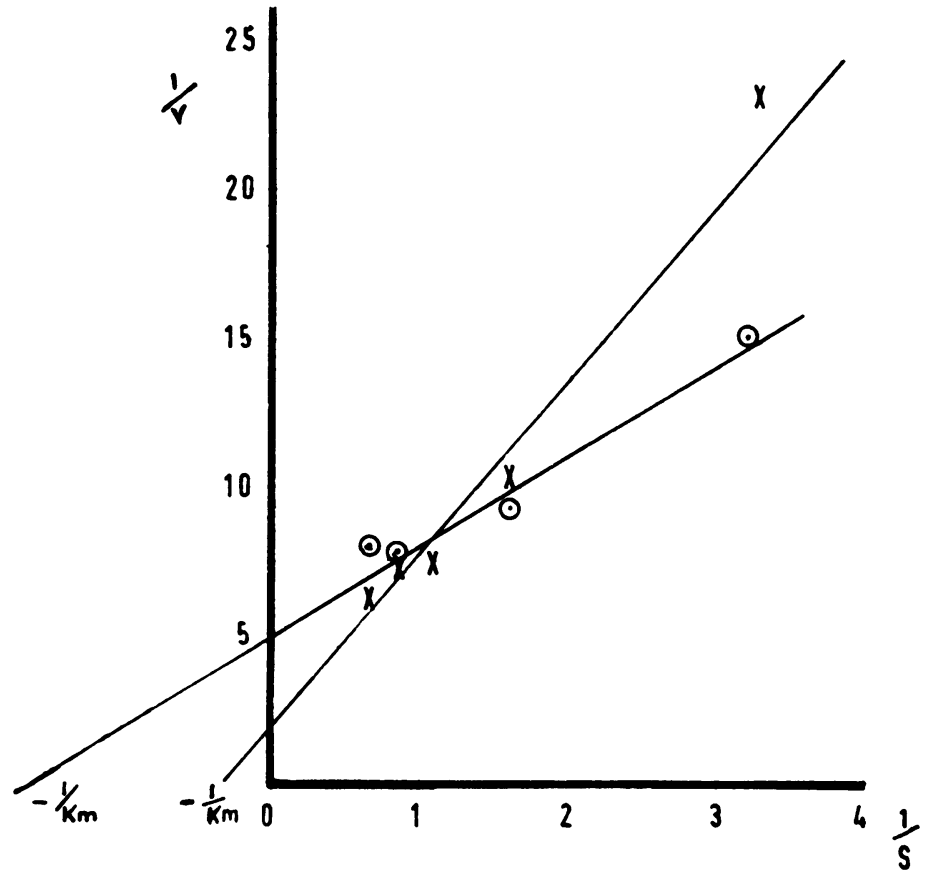

Fig. 1 Lineweaver-Burke plot for $K_{m} \stackrel{\text { ڤ̆ }}{8}$ (substrate carbamoyl phosphate) of ornithine carbamoyltransferase from the liver of a child without

hyperammonaemia $(\times-\times)$ and of a patient with hyperammonaemia due to 露 altered ornithine carbamoyltransferase $(\odot-\odot)$. Normal value for $K_{m}$ is $1.79 \widehat{ }$ $\pm 0.16 \mathrm{mM}$; that of this patient was $0 \cdot 34 m M$. 
substrate. This constant may change if the structure of the enzyme is abnormal. For example, in one child with hyperammonaemia, the $\mathrm{K}_{\mathrm{m}}$ of ornithine carbamoyltransferase (EC 2.1.3.3) was abnormal, although the activity as measured in vitro was only slightly below the normal range (Levin, Dobbs, Burgess, and Palmer, 1969). This pointed to a defect in enzyme structure sufficient probably to cause a marked decrease in enzyme activity in vivo (Fig. 1).

Again, the lactate dehydrogenase (EC 1.1.1.27) of muscle from muscular dystrophy has not the isoenzyme pattern of normal muscle. There is some evidence from starch gell electrophoresis that the lactate dehydrogenase from the liver of one infant with lactic acidaemia had an abnormal isoenzyme pattern although the total activity was within the normal range (B. Levin and E. A. Burgess, unpublished observations).

Even if the enzyme level in the patient is too low for measurement of its $\mathrm{Km}$ value, relatives whose enzyme activity is measurable may be found to have an enzyme with an altered $K_{m}$ value. This was so in the parents of a child who died in a severe haemolytic episode due to the virtual absence of glucose 6phosphate dehydrogenase (EC 1.1.1.49) in the red cells (B. Levin and E. A. Burgess, unpublished observation). Such deviation of $\mathrm{Km}$ values must be quite large before the enzymecan be considered as abnormal.

The decision that an enzyme activity is quantitatively abnormal is made by comparison with the range found in normal tissues. However, an examination of the literature concerned with the determination of the activity of almost any enzyme in human disease will show a surprisingly wide variation in the normal ranges of values quoted, possibly due to variation of laboratory technique and method. It is advisable for each worker to establish his own normal range, if possible.

\section{Micro and Ultramicro Techniques}

Since the amounts of tissue available are very small, it is necessary to use micro methods. The simplest and commonest way of achieving this is to scale down the amounts, making the final measurement in a microcuvette. Micro constriction pipettes and small tubes are necessary.

Ultramicro methods involve the use of radioactive substrates or of fluorimetry. Both methods have their own special problems, but if these can be overcome they allow the enzyme to be assayed with very much smaller amounts of tissue than used in micro methods. They are especially useful if assays are to be performed on white blood cells or on liver biopsies taken percutaneously.

When a radioactive substrate is used it is necessary to separate the labelled product from the substrate after the reaction is completed, so that the change in concentration of either substrate or product may be determined by counting the radioactivity. This can be achieved by several methods: (1) By paper chromatography or electrophoresis, when substrate and product are chemically similar, eg, methylmalonyl-CoA mutase (EC 5.4.99.2), where methylmalonic acid is to be separated from succinic acid (Oberholzer, Levin, Burgess, and Young 1967). (2) By precipitation, when glycogen debrancher enzyme is assayed, eg, the radioactive product, glycogen, is precipitated and washed free from the labelled glucose (Hers, 1959). (3) Carboxylyases can be assayed using ${ }^{14} \mathrm{C}$-labelled carbonate or bicarbonate as substrate. The excess carbonate is removed from the mixture after completion of the reaction by acidification and then leaving the tubes in a vacuum over $\mathrm{NaOH}$. The radioactivity left in the solution is now in the carboxylated product.

Although fluorimetric methods are capable of high sensitivity they are limited to the assay of those enzymes whose substrates or products can be made to fluoresce. They can be used to assay dehydrogenases, since NAD and NADP fluoresce, especially in alkaline solution. They are also useful in assaying certain hydrolases, such as glycoside hydrolases, where an artificial glycoside containing a 4-methylumbelliferyl group can be used as substrate. These are especially important for the assay of the lysosomal acid glycoside hydrolases in the mucopolysaccharidoses.

\section{Sample Treatment}

Ideally, for the assay of enzyme activity in tissue, fresh material should be used immediately after removal at operation. The tissue is collected in the operating theatre in a clean, dry tube or jar, placed in a vacuum flask containing ice and sent at once to the laboratory. An intestinal biopsy is rinsed with cold saline in a small watch glass and usually examined rapidly with the dissecting microscope before assay of the enzymes.

If the tissue cannot be assayed at once, or if it is to be sent to another hospital, it should be wrapped gently in clean foil, placed in as small a vessel as is possible, and immersed in solid carbon dioxide in a vacuum flask so that the tissue is frozen as quickly as possible after removal from the patient. It must not be thawed until the assays can be performed.

It must be remembered when assaying enzyme activities in tissue homogenates that a very complicated mixture of enzymes is present. It is important to be sure that these do not interfere with the reaction being studied, either by competing for 
the substrate or cofactors, or by reacting with the product of the reaction. A knowledge of the properties of the enzyme under study, of its relationship to other enzymes and metabolic pathways, and of its location within the cell, will enable one either to prevent or to make use of these secondary reactions.

The first property of the enzyme to be considered is its stability in warm or cold conditions. Most of the commonly measured enzymes are stable if kept frozen as described. However, there are a few which are either unstable at low temperatures and should never be frozen, or lose activity if they are repeatedly frozen and thawed. An example of the first is glucokinase (EC 2.7.1.2.), which must always be measured in fresh tissue, without freezing. It should also be remembered that freezing and thawing of tissue causes rupture of both tissues and particulate membranes, so that when particles such as mitochondria, lysosomes, and microsomes are to be isolated, the tissue must not be frozen before homogenization.

\section{Preparation of Homogenate}

Because enzymes are frequently unstable in some degree to repeated freezing and thawing, it is not advisable to thaw the tissue each time a portion is required for enzyme assay. Most enzymes appear to be more stable in whole tissue than in the homogenate. It is best to keep the tissue frozen, removing minimal amounts from the frozen piece as required and to prepare only the volume of homogenate needed at one time.

In our laboratory, the tissue is homogenized in an all glass Ten Broek grinder of a size appropriate to the volume of homogenate required. The type of medium required for homogenization varies. Many enzymes are stable in a water homogenate, do not need to be buffered at a specific $p \mathrm{H}$, and do not require the addition of reagents to maintain the stability of the enzyme structure. Others lose activity rapidly unless the homogenate is buffered. A number of enzymes require a reduced sulphydryl group at or near their active centre, and with such enzymes the addition of reduced glutathione or other reduced sulphydryl compound to the homogenate is necessary to protect the sulphydryl group in the protein from oxidation.

When the enzyme is situated within intracellular particles such as mitochondria or lysosomes, it is sometimes impossible to assay in an ordinary homogenate because the particle membrane may be impermeable to the substrate. In that case, it may be necessary to add a non-ionic detergent such as Triton X 100 in order to lyse the particles. If the particles are to be preserved, however, the homo- genate is made in isotonic sucrose solution so that they can be separated by differential centrifugation Muscle needs to be cut roughly with scissors befor $\overline{5}$ homogenizing, and a loose-fitting homogenizer is used. For liver and intestine, it is better to use tight-fitting homogenizer.

\section{Methods of Enzyme Assay}

The activity of an enzyme is determined from the rate at which the catalysed reaction proceeds. Tw $\mathscr{Q}$ general methods are available for performing enzyme assays. In the first, a homogenate is incubated at $37^{\circ} \mathrm{C}$ in a medium buffered at a suitable $p H$ anf containing the substrate and any cofactors requirect. Aliquots are removed at zero time and at timeg intervals thereafter, each being pipetted into $\vec{a}$ protein precipitant, which stops the reaction. Provided there is enough tissue available, it is advisable to take samples at several timed intervals This is preferable to performing the assay in dupli? cate at one time interval, since it ensures that the $\vec{e}$ reaction is proceeding linearly, while providing mores than one reading to eliminate errors. The amount of substrate used or of product formed is then measure

In the second method the reagent mix is actuall 5 incubated in the spectrophotometer cuvette, and ghe change in concentration of one of the components of the reaction is directly followed by measuring absorption at the required wavelength at suito intervals of time. This method is used especially fo dehydrogenase reactions, where advantage is take of the absorption at $340 \mathrm{~nm}$ of reduced pyridine nucleotides.

The concentration of the homogenate and time of incubation must be selected to ensure that the reaction studied proceeds linearly over the period of the incubation. A high concentration of substrate should be present, so that there is an excess during the whole course of the reaction; a concentration of. five to ten times the smallest amount necessary to produce the maximum rate of enzyme reaction 0 usually used. This can be calculated from the Michaelis constant of the enzyme if this is known? An example of a poorly devised assay method frot this point of view is one commonly described for the: assay of red cell galactose 1-phosphate uridyfs transferase (EC 2.7.7.10) activity (Fig. 2). This recommends that one reading only be taken aftêt 30 minutes' incubation. Calculation from this yields normal levels of $1 \cdot 7-9 \cdot 0$ units/gHb as usualk quoted. However, if several timed samples are removed for assay of residual UDPglucose, becomes apparent that the reaction is not linear over this period and a much higher normal range is found if the results are calculated from the initial part of 


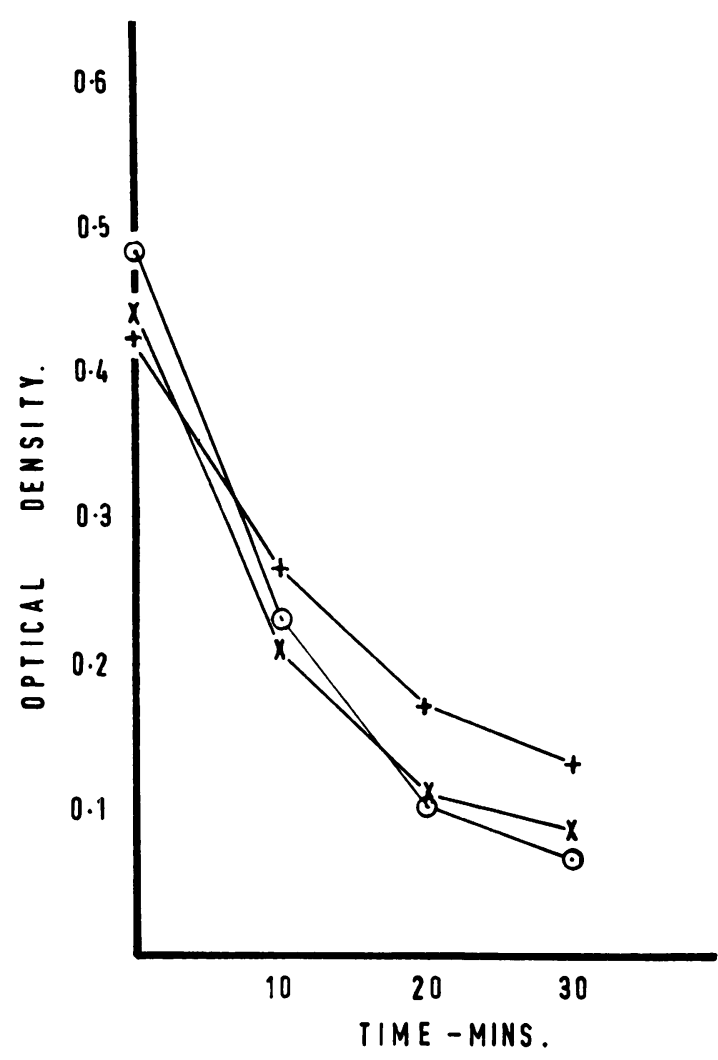

Fig. 2 Assay of galactose 1-phosphate uridylyltransferase in red blood cells from three normal individuals.

Reaction: UDPGluc + Gal-1-P $\rightarrow$ UDPGal + G-1-P. Residual UDPG is measured at the time intervals shown.

the curve which is linear. This may not be important in judging whether or not an enzyme is present or absent for the purpose of diagnosis of the condition, but becomes important if the heterozygote state is to be detected.

After the incubation, the reaction product is assayed in the protein-free filtrate. This can often be done in the presence of the substrate, as for example with glucose 6-phosphatase (Fig. 3) where inorganic phosphate is measured in the presence of the acid stable glucose 6-phosphate, or with ornithine carbamoyltransferase, where citrulline is assayed in the presence of ornithine. Often, however, the product, being chemically similar to the substrate, cannot be assayed in its presence. The two may then be separated by paper chromatography or electrophoresis so that they may be measured separately as in the case of methylmalonyl-CoA mutase (Oberholzer et al, 1967). When the product of the

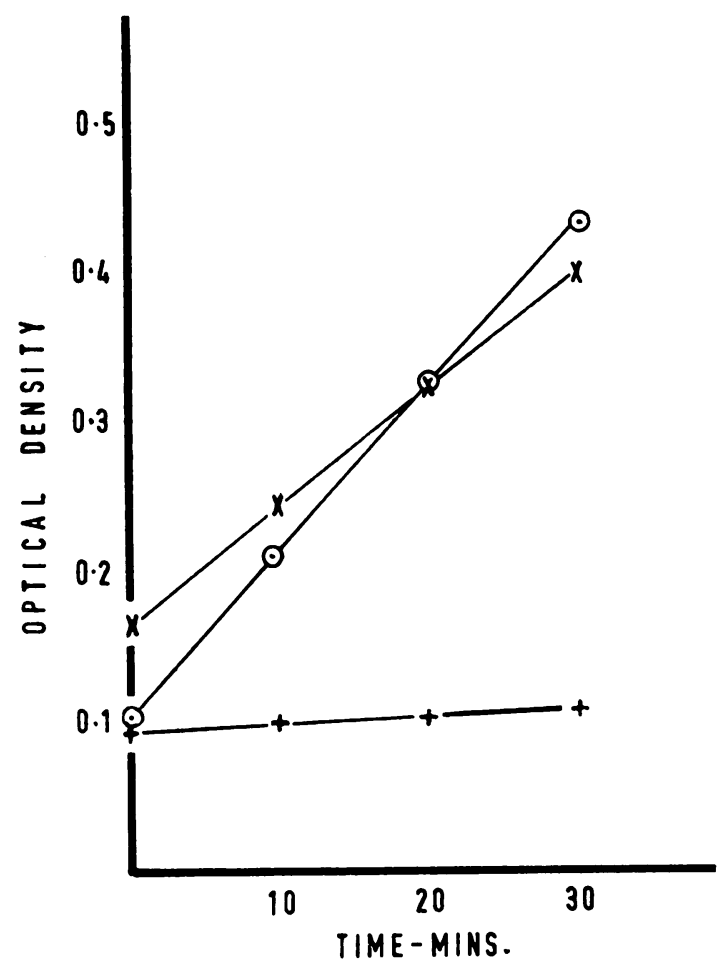

Fig. 3 Assay of glucose 6-phosphatase in liver. The low rate of reaction in glycogen storage disease type $I$ $(+-+)$ as compared with normal $(\times-\times)$ is shown. In fructosaemia $(\odot-\odot)$, glucose 6-phosphate accumulates, inducing a higher activity of glucose 6phosphatase.

Reaction: G-6-P $\rightarrow$ Glucose + inorganic phosphate. The increase in inorganic phosphate is measured.

enzyme under study inhibits the enzyme reaction, or is unstable, it can be converted in situ by a second enzyme system, using the product of the initial reaction as its substrate. This second enzyme is added in excess, so that conversion of the product is quantitative. The final end product is then assayed in the protein-free filtrate.

It is important to consider also the relationship of the enzyme to be assayed to other enzymes and to the metabolic pathway involved. There may be present in the homogenate other enzymes which are likely to compete for the substrate, or subsequent enzymes of the pathway may act upon the product of the reaction under examination so that it cannot now be accurately measured. Thus the method mentioned above for the assay of galactose 1-phosphate uridyltransferase in red cells cannot be used with liver since UDPglucose epimerase (EC 5.1.3.2.) will reconvert UDPgalactose to UDPglucose. For its 
assay in liver, the glucose 1-phosphate is determined by conversion to glucose 6-phosphate by adding phosphoglucomutase (EC 2.7.5.1.) (Roth, Segal, and Bertoli, 1965).

Enzymes which catalyse a single reaction, eg, the disaccharidases or which, although in a metabolic sequence, yield a product which does not undergo further change, eg, arginase, can usually be readily assayed by measuring the product. On the other hand, two enzymes of the urea cycle, argininosuccinate synthetase (EC 6.3.4.5) and argininosuccinate (EC 4.3.2.1) lyase, may be measured by encouraging their products to continue quantitatively to the formation of urea by adding purified arginase to the reaction mixture.

In some cases where the enzyme to be measured forms part of a metabolic pathway, the immediate product does not accumulate quantitatively, nor can the final product of the pathway be quantitatively produced. This difficulty can be overcome by adding an inhibitor of the subsequent enzyme of the sequence, thus allowing the product of the reaction to accunilate. For example, when fructose-diphosphate aldolase (EC 4.1.2.13), an enzyme in the glycolytic pathway, is assayed in liver or muscle biopsies, iodoacetate can be added as inhibitor of the next reaction in the glycolytic sequence; in this case it is also necessary to remove the products of the reaction, glyceraldehyde phosphate and dihydroxyacetone phosphate, as they are formed, since if allowed to accumulate they inhibit the activity of the aldolase. Both products form hydrazones so that hydrazine hydrate is added to prevent their inhibitory action.

An alternative method of assaying an enzyme in the middle of a metabolic sequence is to measure the rate of disappearance of the substrate. Thus, methylmalonyl-CoA mutase converts methylmalonyl-CoA to succinyl-CoA which cannot be assayed because it is metabolised by the tricarboxylic acid cycle. Its further metabolism could be suppressed by malonic acid which inhibits succinate dehydrogenase (EC 1.3.99.1) were it not for the fact that malonic acid also inhibits methylmalonyl-CoA mutase.

An enzyme from a different or an opposing metabolic sequence may utilize either the same substrate or the cofactors of the enzyme being studied. Thus, when ATP is an obligatory cofactor in a reaction, it is necessary to ensure that neither the specific ATP-ase (EC 3.6.1.3.) nor nonspecific phosphatases destroy the ATP. Since fluoride is an effective inhibitor of ATP-ases, it is sometimes helpful to add this, provided that it does not also inhibit the enzyme under study. One way of removing ATPase is to remove the microsomes by centrifugation since they contain the highest concentration of
ATP-ase. A more convenient method is to add a ATP-regenerating system such as phosphoenode pyruvate and pyruvate kinase (EC 2.7.1.40).

\section{Summary and Conclusion}

The purpose of emphasizing the difficulties involve in the assay of enzymes in tissues is to point out tha the methods developed for the assay of purifie enzymes cannot be applied without modification t8 the assay of the enzymes in a tissue homogenate. Proper attention must be given to the preparation of the tissue and indiscriminate deep freezing is to be avoided. Provided the conditions are chosen so th the reaction is linear over the period of assays methods which are relatively simple to perform cals be devised for the assay of most of the enzymes of interest in metabolic defects. The finding of absertit or low activity of one enzyme together with a normab activity of other enzymes in the same sequence is sufficient to show the cause of the metabolic ab normality. This does not establish in itself whether the enzyme protein has been completely deleted of whether there is a normal amount of enzyme protein with an abnormal structure. The presence of enzymes with abnormal $K_{m}$ values in some ins stances of metabolic block suggests that the second possibility may sometimes be the case. For this reason it is interesting to study the properties of the enzyme as well as measuring its activity. It is offer necessary to assay several enzymes of a metabol $\bar{c}$ sequence under investigation, not only to prove the one defective enzyme activity exists, but that othef enzymes of the series are normal.

References

Auerbach, V. H., and DiGeorge, A. M. (1965). Genetic mechanismis producing multiple enzyme defects. A review of unexplaine्त. cases and a new hypothesis. Amer. J. med. Sci., 249, 719-74प,

Hers, H. G. (1959). Etudes enzymatiques sur fragments hépatiquẹ্]; application à la classification des glycogénosis. Rev. i]ت. Hépat., 9, 35-55.

Levin, B., Snodgrass, G. J. A. I., Oberholzer, V. G., Burgess, E. A, and Dobbs, R. H. (1968). Fructosaemia. Observations of seven cases. Amer. J. Med., 45, 826-838.

Levin, B., Dobbs, R. H., Burgess, E. A., and Palmer, T. (196\%. Hyperammonaemia. A variant type of deficiency of liver ornithine transcarbamylase. Arch. Dis. Childh., 44, 162-16.

Oberholzer, V. G., Levin, B., Burgess, E. Ann, and Young, F. (1967). Methylmalonic aciduria. An inborn error metabolism leading to chronic metabolic acidosis. Arab Dis. Childh., 42, 492-504.

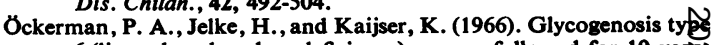
6 (liver phosphorylase deficiency); a case followed for 10 years with normal phosphorylase activity in white blood cells afit jejunal mucosa. Acta paediat. scand., 55, 10-16.

Parr, J., Teree, T. M., and Larner, J. (1965). Symptomatic hyp§glycemia, visceral fatty metamorphosis, and aglycogenosis in an infant lacking glycogen synthetase and phosphorylas. Pediatrics, 35, 770-777.

Roth, H., Segal, S., and Bertoli, D. (1965). The quantitative deterrmination of galactose-an enzymic method using galactost oxidase, with applications to blood and other biological fluigs. Analyt. Biochem., 10 32-52. 